\title{
Surface kinematics of periglacial sorted circles using structure-from-motion technology
}

\author{
A. Kääb ${ }^{1}$, L. Girod ${ }^{1}$, and I. Berthling ${ }^{2}$ \\ ${ }^{1}$ Department of Geosciences, University of Oslo, P.O. Box 1047, Oslo, Norway \\ ${ }^{2}$ Department of Geography, Norwegian University of Science and Technology, 7491 Trondheim, Norway
}

Correspondence to: A. Kääb (kaeaeb@geo.uio.no)

Received: 26 November 2013 - Published in The Cryosphere Discuss.: 18 December 2013

Revised: 23 April 2014 - Accepted: 30 April 2014 - Published: 11 June 2014

\begin{abstract}
Sorted soil circles are a form of periglacial patterned ground that is commonly noted for its striking geometric regularity. They consist of an inner fine domain bordered by gravel rings that rise some decimetres above the fine domain. Field measurements and numerical modelling suggest that these features develop from a convection-like circulation of soil in the active layer of permafrost. The related cyclic burial and exhumation of material is believed to play an important role in the soil carbon cycle of high latitudes. The connection of sorted circles to permafrost conditions and its changes over time make these ground forms potential palaeoclimatic indicators. In this study, we apply for the first time photogrammetric structure-from-motion technology (SfM) to large sets of overlapping terrestrial photos taken in August 2007 and 2010 over three sorted circles at Kvadehuksletta, western Spitsbergen. We retrieve repeat digital elevation models (DEMs) and orthoimages with millimetre resolution and precision. Changes in microrelief over the $3 \mathrm{yr}$ are obtained from DEM differencing and horizontal displacement fields from tracking features between the orthoimages. In the fine domain, surface material moves radially outward at horizontal rates of up to $\sim 2 \mathrm{~cm} \mathrm{yr}^{-1}$. The coarse stones on the inner slopes of the gravel rings move radially inward at similar rates. A number of substantial deviations from this overall radial symmetry, both in horizontal displacements and in microrelief, shed new light on the spatio-temporal evolution of sorted soil circles, and potentially of periglacial patterned ground in general.
\end{abstract}

\section{Introduction}

The term patterned ground describes a range of small-scale (of the order of $0.1-10 \mathrm{~m}$ ) landforms, such as polygons, stripes and circles, found in periglacial environments (Washburn, 1980). Patterned ground develops in frost-susceptible soils due to repeated freezing and thawing (Hallet, 1990). These landforms are considered an excellent geomorphic example of self-organization and emergence in complex systems (e.g. Kessler et al., 2001; Kessler and Werner, 2003). The most prominent forms of this type are found in the active layer of Arctic or Antarctic lowland permafrost, where the permanently frozen subsurface confines water and creates hydrological conditions favourable for ice growth in the overlying layer of seasonal freezing and thawing, the so-called active layer.

The most conspicuous type of patterned ground is sorted circles, or stone circles (Hallet, 2013). They consist of a core of fine-grained material (here termed fine domain), reaching a depth of at least the active layer, surrounded by a much coarser circular border or ridge of open-work fabric that extends $1-5 \mathrm{dm}$ above the centre surface (here termed gravel rings) (Figs. 1-3). Typical diameters for the fine domains are $1-3 \mathrm{~m}$, whereas the gravel rings may be $0.5-1 \mathrm{~m}$ wide. Much smaller forms are also found (e.g. Matsuoka et al., 2003). The surface material in the centre domain shows a radial outward movement of the order of $0.01 \mathrm{~m} \mathrm{yr}^{-1}$ (Schmertmann and Taylor, 1965; Hallet and Prestrud, 1986; Washburn, 1989; Hallet, 2013), and from measuring the tilt of inserted rods similar movement extends to a depth of decimetres (Hallet, 1998, 2013). For mass continuity reasons, this suggests that the soil within the fine domains follows a displacement 


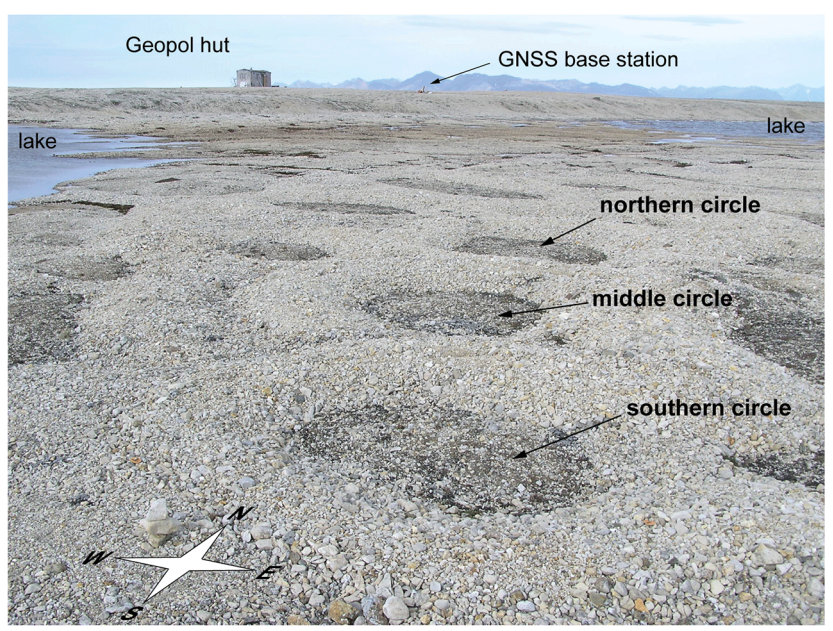

Figure 1. Photo of site and sorted circles studied. The darker, inner parts of the circles have a diameter of around $1.5 \mathrm{~m}$ on average. View is to the north.

pattern similar to a convection cell. This burial - and later resurfacing - of material in patterned ground is an important element within the soil carbon cycle of high latitudes (e.g. Bockheim, 2007; Horwath et al., 2008) as well as soil development (e.g. Bockheim et al., 1998). It also highlights that precise knowledge about patterned-ground dynamics has implications far beyond the geomorphic interest in processform relationships - especially with respect to the effect of warming air and ground temperatures on soil carbon stocks. Moreover, patterned ground is considered a potential palaeoclimatic indicator based on the general relation between pattern size and permafrost conditions such as active layer depth (Hallet and Prestrud, 1986).

A variety of mechanisms have been suggested for the origin of sorted circles and other patterned-ground landforms (cf. Washburn, 1980), but recent work has focussed on differential frost heave (e.g. Peterson, 2008), and its feedback with progressive sorting (e.g. Kessler et al., 2001; Kessler and Werner, 2003; Hallet, 2013). Scientific progress within this field comprises thorough field investigations, laboratory work and theoretical studies (Hallet, 1998, 2013), as well as numerical models of the development of unsorted circles (Peterson and Krantz, 2008), sorted circles and other sorted patterned-ground landforms (Kessler et al., 2001; Kessler and Werner, 2003). In the model of Kessler and Werner (2003), two main feedback mechanisms determine the development of circles from the starting point of a nearly uniform stone layer overlying fine-grained soil. First, soil and stones are transported in opposite directions normal to the freezing front during freeze-thaw cycles, with an increasing lateral component because the freezing front reaches deeper under stone accumulations. The relief of the freezing front thus increases with increasing stone clustering. Second, as stones are sorted through time, they form elongated regions,

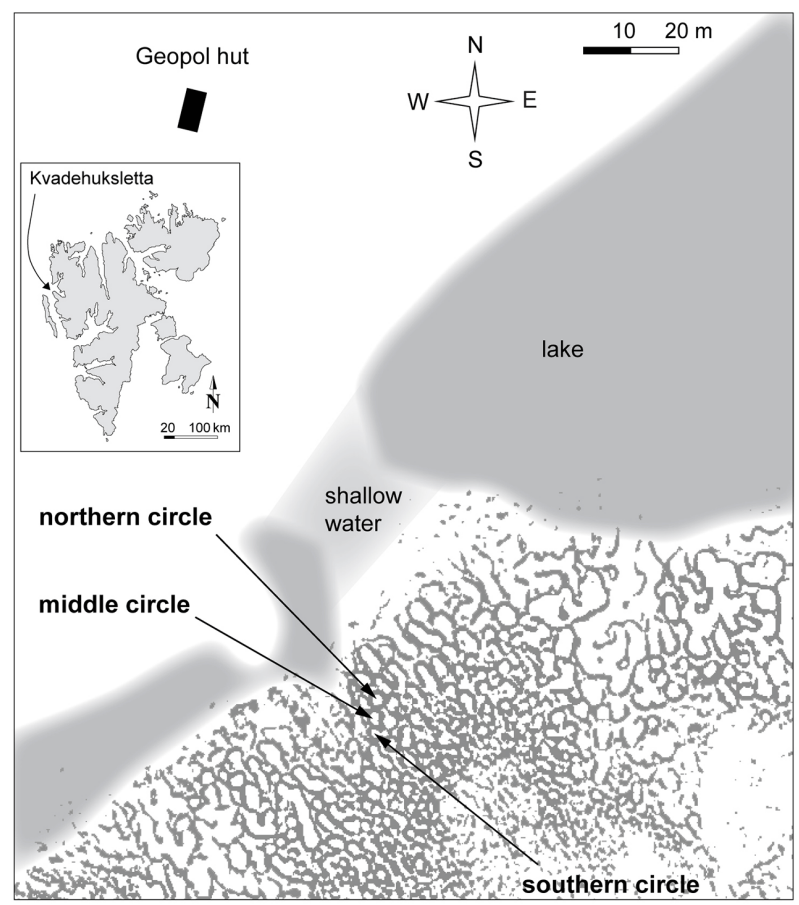

Figure 2. Sketch map of the study site and stone circles investigated. The grey pattern shows gravel rings and ridges extracted from a high-resolution satellite image of June 2012. The inset map indicates the site location on Svalbard.

and the stone domains are progressively squeezed by the fine domains during winter freeze-up, when the rapidly cooling stone domain causes lateral frost heave within the fine domain. Pattern types change in model runs due to increasing slope (causing stripes to develop), decreasing stone concentration (leading to stone labyrinths and stone islands) and increasing lateral confinement (favouring polygonal patterns).

The model of Kessler and Werner (2003) can be considered a hypothesis for the main mechanisms involved in patterned-ground formation. It provides specific predictions about the dynamics of central and border domains. Whereas existing empirical data of sorted circle dynamics consist only of point measurements (e.g. Hallet and Prestrud, 1986; Hallet, 1998, 2013), measurements of the three-dimensional surface displacement fields and microtopography are feasible today - even over short timescales. Such data would be considerably better suited to test these predictions than the sparse data currently available. A comprehensive benchmark of present-day dynamics would aid research on the influence of changes in the underlying frozen ground on circle dynamics, which is linked to the potential importance of cryoturbation and differential frost heave in the global carbon cycle. Ultimately, better understanding of the processes involved in the dynamics of patterned ground and their changes over time would facilitate their use as an indicator for present and past environmental conditions in cold regions. Our objective is thus to test a methodology for deriving the 3-D surface 


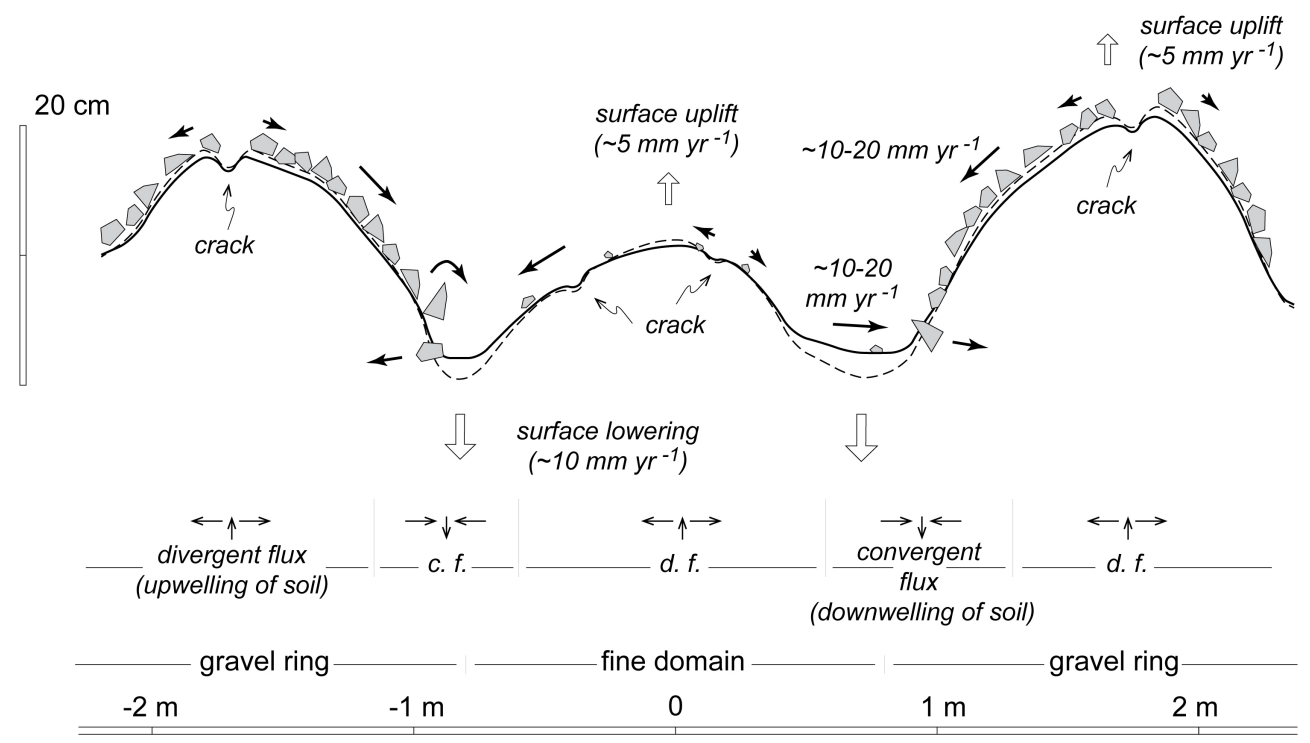

Figure 3. Generalized surface cross section and findings regarding changes over 2007-2010 on the stone circles of this study. The topographic profile shown is approximately a southwest-northeast cross section over the centre of the middle circle. The solid line indicates the year 2007, and the dashed line 2010. Black arrows indicate soil surface movement, and the white vertical arrows surface elevation changes. Vertical exaggeration is five-fold.

kinematics of sorted stone circles, and to analyse our initial data with respect to predictions from conceptual and numerical models.

To quantify the surface kinematics of selected sorted circles we apply structure-from-motion (SfM) technology to a multi-temporal set of terrestrial images to derive vertical and horizontal components of change over time. SfM combines well-established photogrammetric principles, in particular bundle adjustment and image matching, with modern computational methods to arrive at a powerful and userfriendly software environment that is able to extract a threedimensional model from a set of images, which then forms the base for a range of further products, among them digital elevation models (DEMs) and orthoimages. SfM technology has already proven to be very powerful for a range of geoscientific applications, such as geological and glaciological studies, coastal erosion, river morphology, volcanic activity or landsliding (e.g. Girod, 2012; James and Robson, 2012; Westoby et al., 2012; Fonstad et al., 2013).

\section{Method}

\subsection{Study site and data collection}

For our study we selected a series of three adjacent sorted circles at Kvadehuksletta, Brøggerhalvøya, western Spitsbergen (Figs. 1 and 2). The circles lie $\sim 130 \mathrm{~m}$ south of the Geopol hut, and $\sim 10-20 \mathrm{~m}$ south of a lake to which the terrain is slightly sloping. The sorted circles at Kvadehuksletta are, to the best of our knowledge, among the best developed of their kind on Earth, and comparably easy to access, located $\sim 10 \mathrm{~km}$ to the northwest from the Ny-Ålesund research station. As a result, these circles have been subject to a number of earlier investigations (Hallet and Prestrud, 1986; Anderson, 1988; Hallet et al., 1988, 1998, 2013; Etzelmüller and Sollid, 1991; Putkonen, 1998), and a detailed geomorphological map is also available (Tolgensbakk and Sollid, 1987).

Kvadehuksletta is a wide strandflat, covered with beach deposits of Holocene age and older. Our study site is situated above the Holocene marine limit. The overall elevation of the circles studied is $\sim 53 \mathrm{~m}$ a.s.l. Bedrock in the area consists of dolomite, and most of the beach-ridge stones are of local origin. Due to weathering of the dolomite and subsequent eluviation, a frost-susceptible silty fine-grained soil has developed (Etzelmüller and Sollid, 1991), which facilitates development of sorted circles. Large areas between the beach ridges are covered by such sorted circles, grading in some areas towards sorted polygons and more irregular sorted forms as well as stripes on slopes (Tolgensbakk and Sollid, 1987). The fine domains of the circles often have a variable cover of vegetation, mainly dominated by cryptogamic crust, that gives the inner circle a dark appearance, but sometimes also with higher plants such as sedges and salix. The vegetation tends to be densest close to gravel ridges, and shows evidence of the surface movement pattern. Salix is also on some gravel rings.

Climatic data are available from $\mathrm{Ny}-\mathrm{A}$ lesund, where the mean annual air temperature is $-6.3^{\circ} \mathrm{C}$ and mean annual precipitation is $385 \mathrm{~mm}$ for the normal period, 1961-1990. Recent warming in the Arctic areas suggests that these values 

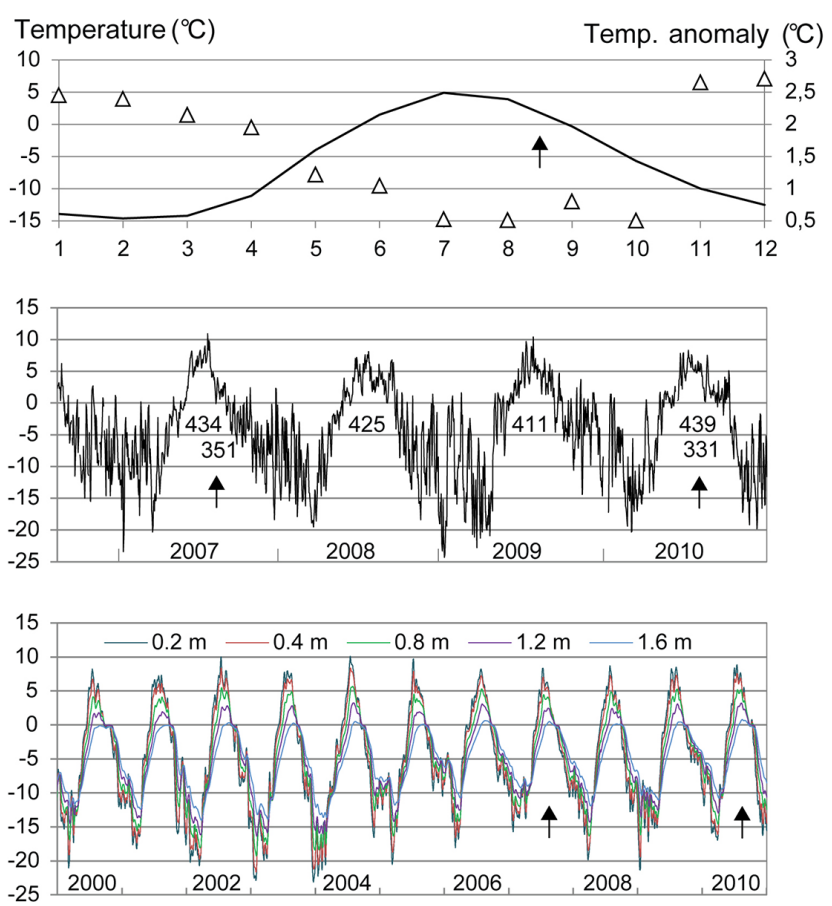

Figure 4. Upper panel: mean monthly air temperature in $\mathrm{Ny}$ Ålesund for the 1961-1990 normal period (solid line). Temperature anomaly for all months calculated as a mean of monthly deviations from normal during the 1991-2010 period (triangles). Middle panel: air temperature in Ny-Ålesund during the September 2006December 2010 period. Degree-day sum during summers of 20072010 displayed within the graph; sum at the time of photography in 2007 and 2010 below. Lower panel: ground temperatures from the shallow Janssonhaugen borehole. Photography dates indicated by arrows. Air temperature data downloaded from eKlima, Norwegian Meteorological Institute. Ground temperature data from K. Isaksen (personal communication, 2013).

may no longer be fully representative (Isaksen et al., 2007a, b), and in Fig. 4 the mean monthly anomaly from the normal, calculated for the period 1991-2010, provides a more realistic picture of the present climatic situation at the site. The anomaly is most pronounced in winter. Figure 4 also displays air temperatures during the study period and melting season degree-day sums, and near-surface temperatures for 19992010 (7-day running mean) from the $15 \mathrm{~m}$ deep Janssonhaugen borehole in bedrock near Longyearbyen (K. Isaksen, personal communication, 2013). Details about the Janssonhaugen site can be found in Isaksen et al. (2001). The recent warming causes warmer ground and a deeper active layer at the Janssonhaugen site, and this is presumably also the case at Kvadehuksletta. Apart from the unusual warm winter of 2005-2006 (Isaksen et al. 2007a), no extreme events likely to influence our measurements are recorded in these data.

Field visits were undertaken in August 2007 and 2010. We used a $\sim 3 \mathrm{~m}$ high ladder in different positions to collect a large number of overlapping images over the adja-

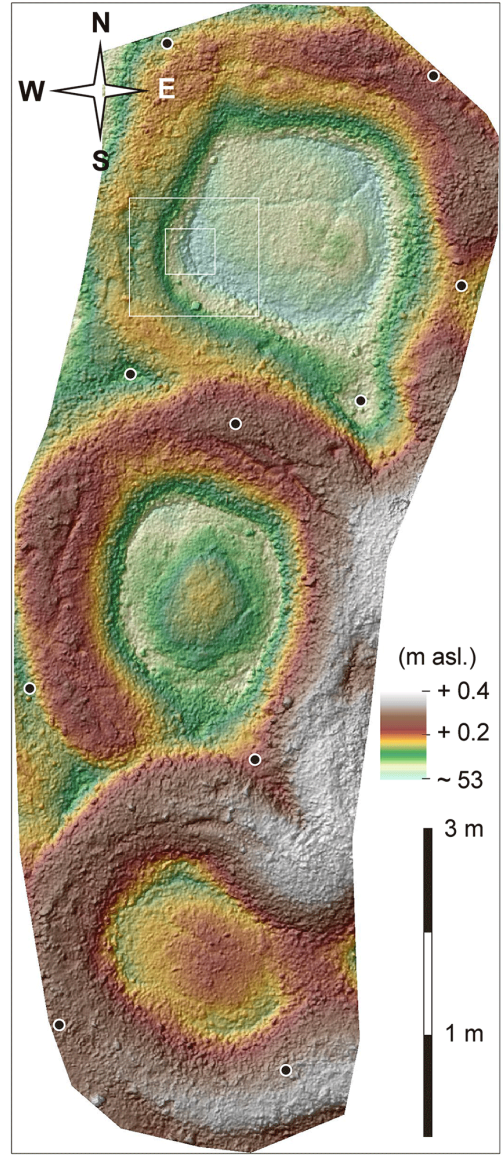

Figure 5. Shaded relief (hillshade) of the 2007 DEM, resampled to $2 \mathrm{~cm}$ resolution, over the three sorted circles with colour-coded elevation superimposed. Black dots indicate the positions of the ground control points used. The larger rectangle in the southwestern part of the northern circle outlines the location shown in Fig. 6, and the smaller rectangle that shown in Fig. 10. Note the soil cracks on the gravel ring tops and on the inner domains.

cent three circles studied. For both acquisition campaigns, a Canon EOS 10D camera with a resolution of $3072 \times 2048$ pixels was used with a fixed focal length of $20 \mathrm{~mm}$. On 9 August 200763 images were taken; 104 were taken on 14 August 2010.

As ground control points, $10 \sim 10 \mathrm{~cm}$ long metal bolts with a round metal plate mounted on top of them were pushed into the ground until the top plate was level with the ground. The points were well distributed over the site imaged (Fig. 5). Vertical and horizontal changes between the 2007 and 2010 images were analysed as relative displacements, because the setup for absolute georeferencing turned out to be insufficient to capture the three-dimensional changes of the ground control positions over $3 \mathrm{yr}$ accurately enough. Nevertheless, we briefly outline here our surveying procedure in order to indicate potential future improvements. At both campaigns, in 2007 and again in 2010, the position of 

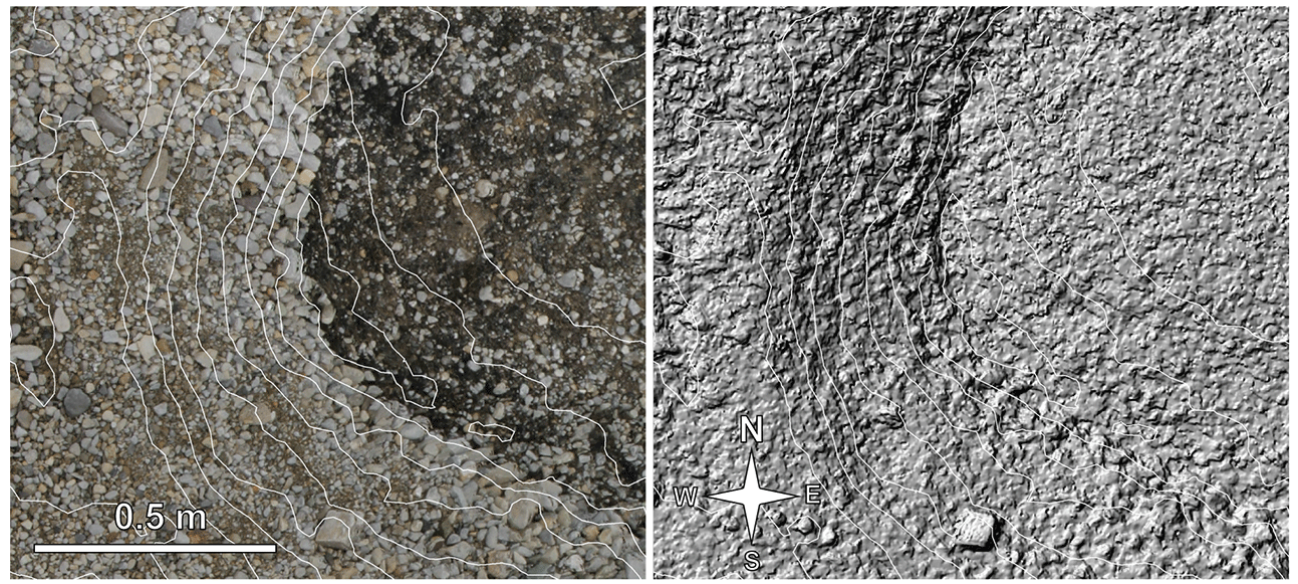

Figure 6. Section of the 2010 orthophoto (left) and DEM hillshade (right). South-western part of the northern sorted circle; for location see Fig. 5. The contour interval is $2 \mathrm{~cm}$ (white lines).

the control points was surveyed using differential global navigation satellite systems (GNSS, a group of systems including GPS) relative to a mark in a rock close to the Geopol hut (Fig. 1). In 2010, the bolt plates were heaved by a few centimetres and had to be pressed back down to ground level in order to be stable enough for placing the GNSS antenna on them. The GNSS network adjustments suggest a relative accuracy of the control points of a few millimetres. However, the fact that (i) the bolts had to be fixed again before the 2010 measurement, that (ii) GNSS elevation is often less well determined than horizontal GNSS position (in particular in high latitudes with low satellite altitude angles), and that (iii) the reference rock at Geopol hut is not bedrock and its position was thus also expected to be affected by frost processes prevents the drawing of sound conclusions from the GNSS positions between 2007 and 2010, and thus for absolute horizontal and vertical displacements of the studied circles as a whole.

\subsection{Image processing}

For both campaigns separately, the ladder images were combined to a three-dimensional model using SfM technology (see Introduction and, for example, James and Robson, 2012; Westoby et al., 2012; Fonstad et al., 2013). SfM does not require the position and looking direction of the camera, or alternatively the 3-D position of control points, to be known before constructing a point cloud based on a set of overlapping images. Independent 3-D positions of control points recognizable in the point cloud are, however, in a later step necessary to enable the absolute orientation. Here, we used the software MicMac (Pierrot-Deseilligny and Clery, 2011, 2012; MicMac, 2014), and processing consisted of the following, mostly fully automatic steps:
1. Find a set of corresponding points (tie points) between images using the SIFT algorithm (scale-invariant feature transform), of the order of $10^{3}$ points per image;

2. compute the position and orientation of the viewpoints, as well as the camera's internal parameters (focal length, distortion, etc.) from the tie points through bundle adjustment.

3. Record the position of the GCPs (ground control points) in the images (2-D coordinates in pixels) and transform the GCP absolute coordinates into an Euclidian projection system (a local tangential coordinate system is commonly used).

4. Perform scaling and rotation of the viewpoint positions and orientations using the information of steps 2 and 3 .

5. Perform a dense correlation based on the data from step 4. This correlation computes the 3-D positions of each point of a $1 \mathrm{~mm}$ spaced regular grid that can be seen in two or more images through the intersection of projection rays. The result of this step is a georeferenced depth map.

6. Project the images on the depth map, producing an orthoimage and a point cloud of the scene.

This process was used for the image sets of 9 August 2007 and 14 August 2010. From the resulting point clouds of approximately 30 million points each, DEMs and orthoimages of $1 \mathrm{~mm}$ horizontal resolution were produced (Figs. 5 and 6). For most analyses, however, the DEMs and orthoimages were resampled to $2 \mathrm{~mm}$ resolution to speed up computations and display. For visualization and some analyses, 1, 2 and $5 \mathrm{~cm}$ versions were also produced.

Vertical differences between the 2007 and 2010 DEMs were obtained by simple subtraction. The two point clouds 

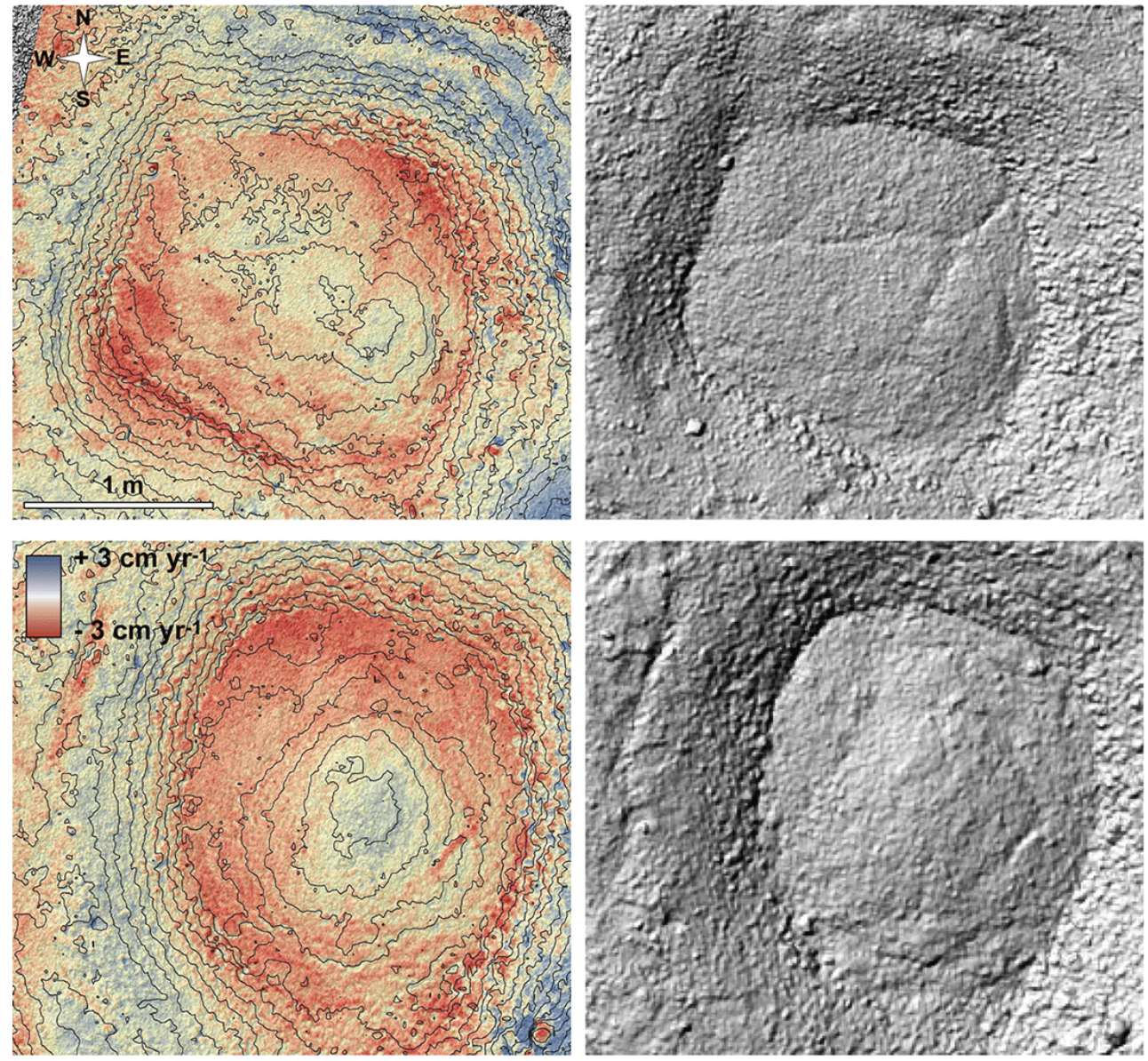

Figure 7. Left: elevation change 2010-2007 on the northern (top) and middle circle (bottom). Two-centimetre contour lines are indicated in black. Right: hillshades of $2 \mathrm{~cm}$ resolution DEM of 2007. The highest parts of the fine domains coincide well with the largest rates of relative surface heave in the fine domain, and the deepest parts with the strongest surface lowering. Note that the horizontal plane of zero elevation change is uncertain due to insufficient absolute georeference; therefore the elevation changes can be interpreted as relative changes in microrelief only.

turned out to be vertically deformed to each other by a few centimetres at the eastern and southern margins (approximately from the top of the gravel rings eastwards and southwards towards the model margins). This deformation could not be repaired in the photogrammetric processing, mainly due to insufficient image coverage and constellations at the eastern and southern model margins. Rather, this effect was in part compensated for by applying a very coarse low-pass filter to the elevation differences and removing the filter results from the raw differences. Nevertheless, elevation differences towards to eastern and southern model margins must be interpreted with care. Further, as an effect of this filter, and in addition to the three-dimensional transformation of the two point clouds onto each other based on the GCPs, the two DEMs are vertically co-registered so that their overall elevation difference roughly equals zero.

Horizontal displacements between the two orthoimages were determined through offset tracking. Using the free soft- ware CIAS (Correlation Image Analysis Software; Kääb and Vollmer, 2000; Heid and Kääb, 2012; Kääb, 2014) and its normalized cross-correlation and orientation correlation algorithms, a $5 \mathrm{~cm}$ spaced grid of displacements was measured based on $10 \mathrm{~cm}$ sized image templates. This large template size, compared to the high image resolution of the order of millimetres, turned out to be necessary to cope with the often individually moving, rotating, or tipping stones that led in part to low visual coherence between the two images. The DEM deformations mentioned above also had an effect on the orthoimages at the southern margin of the photogrammetric model, but only a small effect towards the eastern model margin. As a result, the displacements on the southernmost circle were measured separately from the other two circles after independent co-registration of the two orthoimages using a large number of corresponding points distributed all over the top of the gravel ring where horizontal displacements are assumed minimal. As for the DEM differences, 

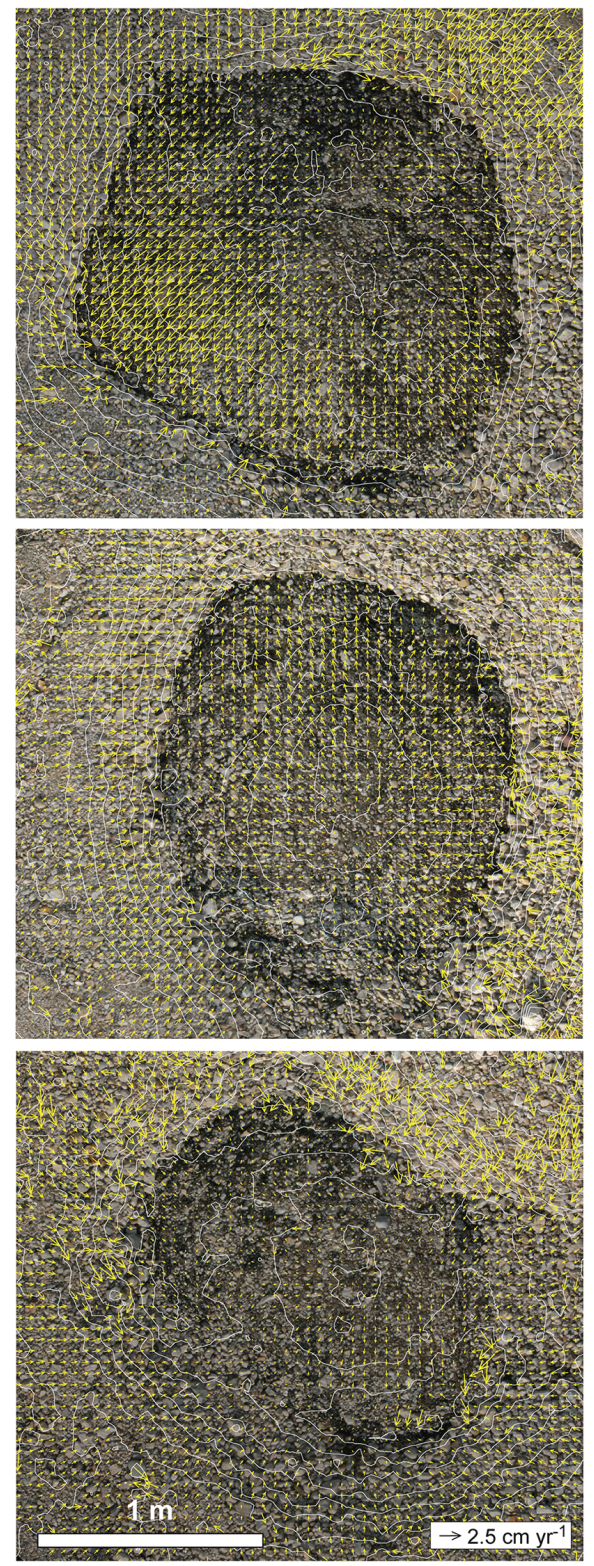

Figure 8. Horizontal surface displacements 2007-2010 on all three circles. Chaotic vectors or groups of vectors are typically caused by individual stones that slide or tip, but could in some cases also be mismatches. Measurements with very low correlation coefficients have been removed. Linear vector scale with maximum vector magnitude of $2.5 \mathrm{~cm} \mathrm{yr}^{-1}$. See Supplement for animated GIFs of the 2007 and 2010 orthoimages.

however, the displacements towards the eastern and southern model margins must be interpreted with care as they could be affected by model distortions of low spatial frequency.

From the displacement field we also compute strain rates in order to map and quantify the degree of soil divergence and convergence at the surface. For that purpose we follow the method outlined by Nye (1959) and use its implementa-

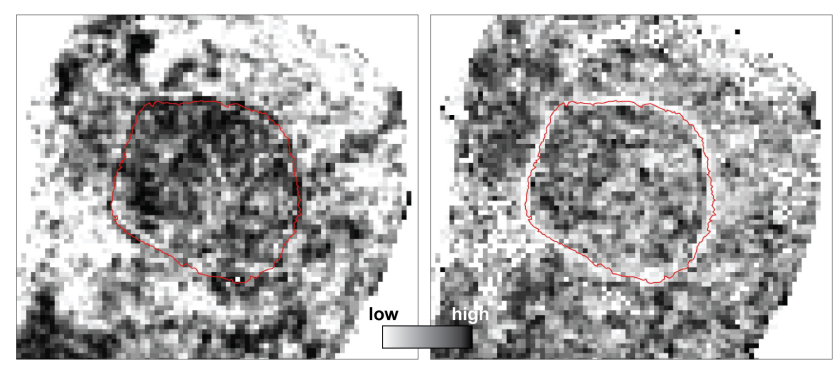

Figure 9. Northern circle. Maximum correlation coefficients (left) and signal-to-noise ratio (SNR, right) of the image matching of Fig. 8. SNR is defined as the ratio between the maximum correlation coefficient and the average correlation coefficient for each individual match. Transition between fine domain and surrounding gravel rings indicated in red.

tion by Kääb and Funk (1999), who derive horizontal strain rates for each point of the displacement grid based on the displacement rates at this position and its four nearest neighbours. As a derivative of the displacement field, strain rates are sensitive to errors in the underlying displacements and thus tend to be considerably more noisy than the original displacement field. Deriving strain rates from five points - the centre and four neighbours - leads to a redundant equation system, and the resulting residual for each strain rate tensor can be used to identify outliers.

\section{Results}

\subsection{Elevation models and differences}

The 2007 and 2010 DEMs offer a large level of detail where, for instance, individual stones can easily be recognized (Figs. 5 and 6). Using some control points that have not been used for absolute orientation as check points, we obtain a standard deviation for elevation of $\pm 6 \mathrm{~mm}\left( \pm 2 \mathrm{~mm} \mathrm{yr}^{-1}\right)$, which we consider to be a reasonable estimate for the vertical accuracy of the DEMs.

The lowest areas of the entire site imaged are the outermost zones of the fine domains, i.e. the fine-coarse border (Figs. 3 and 5). The circle centres are up to $\sim 10 \mathrm{~cm}$ higher than these lowermost zones. The gravel rings have maximum heights of $\sim 20-25 \mathrm{~cm}$ above the fine-coarse boundaries. The northern circle lies roughly $8 \mathrm{~cm}$ lower than the middle circle and $13 \mathrm{~cm}$ lower than the southern circle, measured as differences between maximum elevations of the fine domains (approximately their centres). This overall gradient is in line with the terrain sloping towards the lake to the north of the circles studied (Figs. 1 and 2).

The $1-2 \mathrm{~mm}$ resolution of the DEMs enables recognition of features which are otherwise difficult to detect and map, for instance the cracks that are found both on the inner 

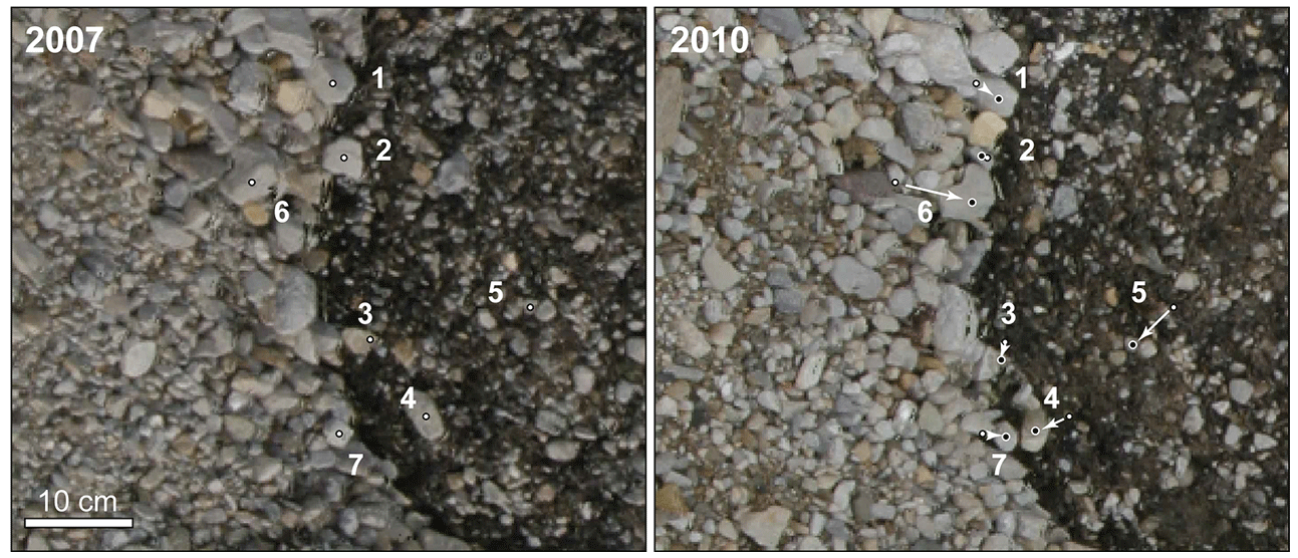

Figure 10. Section of orthoimages for years 2007 and 2010 in the southwestern part of the northern circle. See Fig. 5 for location. Positions of selected stones in 2007 are marked by white dots (left and right), and positions of the corresponding stones in 2010 by black dots (right). Stones 1-3 are in the process of being incorporated into the base of the gravel rings. Stones 4 and 5 move outwards from the circle centre. Stones 6 and 7 fall or slide down the gravel ring. See Supplement for an animated GIF of the 2007 and 2010 orthoimages of the section.

domains and ridges (Fig. 5). Cracks are only found on rather flat sections.

Relative to the overall elevation level of $\sim 53 \mathrm{~m}$ a.s.l., as defined by the control points, and to the vertical coregistration of the two DEMs, the highest zones in the circle centres are stable in elevation or rise by up to $0.7 \mathrm{~cm} \mathrm{yr}^{-1}$ during the measurement period (Fig. 7). Most zones of the fine domain, in particular its outer margins, as well as the lower parts of the inside flanks of the gravel rings, lower consistently, by up to $1.5 \mathrm{~cm} \mathrm{yr}^{-1}$. The gravel ring tops are stable in elevation or rise by up to $1.5 \mathrm{~cm} \mathrm{yr}^{-1}$. For most cracks, both on the gravel rings and in the fine domains, slight elevation losses indicate opening of the crack centre.

\subsection{Orthoimages and displacements}

The 2007 and 2010 orthoimages enable a variety of qualitative and quantitative analyses. The diameters of the inner, fine-grained domains are $\sim 1.8 \mathrm{~m}, \sim 1.6 \mathrm{~m}$ and $\sim 1.5 \mathrm{~m}$ for the northern, middle and southern circles, respectively. Typical stone $b$ axes on the gravel rings range from 1 to $3 \mathrm{~cm}$, but both smaller and larger ones can be found. The larger stones tend to be found at the foot of the inner slope of the gravel rings, whereas the smaller ones dominate the ring tops, where finer, sandy material is also exposed (Fig. 6). The material on the gravel rings appears freshly exposed with no signs of stone stability on the surface such as lichens or weathering. The surface of the inner domains consists mainly of fines, with scattered stones of typical diameters $\sim 1 \mathrm{~cm}$.

Accurate repeat mapping of the fine-coarse boundary between fine domains and gravel rings, which is the clearest type of boundary on the circles, does not reveal any systematic changes between 2007 and 2010. The definition uncertainty of this boundary turned out to be much higher than potential changes within $3 \mathrm{yr}$, as its local changes are mainly governed by moving or tipping stones.

The strikingly high success rate of image correlations over the inner circle parts points to a very coherent deformation over the 3 yr observational period. This is confirmed by flickering the 2007 and 2010 orthoimages, which also suggests a high visual coherence between both data sets (see Supplement). Maximum horizontal surface displacement rates reach $2 \mathrm{~cm} \mathrm{yr}^{-1}$ for the fine domain of the northern circle, $1 \mathrm{~cm} \mathrm{yr}^{-1}$ for the middle circle, and only $3-4 \mathrm{~mm} \mathrm{yr}^{-1}$ for the southern circle (Fig. 8). Overall, for the fine domains of all three circles, the point displacement is radial and outwards. For the northern and middle circles, velocity magnitudes increase away from the centre. The displacement field of the middle circle has one clear centre with zero displacements. Such a centre is less clear for the northern circle, which has, in contrast to the middle circle, two zones with highest elevations, separated by a crack. The displacements on the southern circle are too small to accurately identify the centre of the radial displacements. The centres of the radial displacement fields do not seem to coincide exactly with the highest areas of the fine domains; they are horizontally offset by $\sim 20$ $30 \mathrm{~cm}$ (Fig. A1; see Appendix). The inner part of the northern circle shows a less homogeneous radial displacement field than the middle circle, with scattered zones of comparable high speeds (Fig. A2).

Constructing streamlines through the velocity fields (Kääb et al., 1998) gives surface travel times (approximate surface ages) between the circle centres and the fine-coarse boundary of up to approximately $100 \mathrm{yr}$.

The ratio between speed and the surface slope is for large zones of the fine domains several times larger than for the ring flanks, typically 2-3 times as large, up to 20 times for the western part of the northern circle (Fig. A3). In other words, for a given slope the surface displacements are in 
general much larger in the inner parts of the circles than for the outer rings. As this ratio varies by an order of magnitude even within the fine domains, there is, however, in essence no correlation between speed and slope for these areas.

The displacement field on the gravel rings is much less coherent than on the fine domains. Maximum horizontal speeds on the gravel rings reach $1.5-2.5 \mathrm{~cm} \mathrm{yr}^{-1}$, roughly towards the direction of steepest descent (Fig. A4). Speeds are lowest on the ring tops (Figs. 8 and A2).

\subsection{Surface coherence}

The image matching procedure used here to measure horizontal displacements operates by extracting a $10 \mathrm{~cm} \times 10 \mathrm{~cm}$ large template for each displacement position from the 2007 orthoimage and moving it in pixel-by-pixel steps over a larger search area of the 2010 orthoimage. For each of these steps, the correlation coefficient is computed between the 2007 template and the overlapping image section of 2010, and the maximum correlation coefficient over the search area is assumed to indicate the most probable displacement. Both this maximum correlation coefficient and the average (background) correlation coefficient for a search area are recorded together with the displacement data.

On average, the maximum correlation coefficients are clearly higher on the fine domains than on the gravel rings (Fig. 9). This indicates highly coherent surface deformation on the fines vs. less coherent deformation on the gravel. Orthoimage animation (flickering; see Supplement) confirms that displacements on the gravel rings are often due to sliding or tipping stones (Figs. 8 and 10). The signal-to-noise ratio (SNR) of image matches, i.e. the ratio between the maximum correlation coefficient and the average (background) correlation coefficient for each displacement location, is roughly equal for the gravel rings and the fine domains. This reflects that the lower correlation on the gravel rings affects equally maximum and average correlation values (Fig. 9). However, the transition between fine domains and gravel rings exhibits strikingly low SNRs, indicating that the correlations in this zone are much more weakly defined than on other parts of the circles. Image flickering confirms that the most pronounced visual surface changes are in fact concentrated at this interface, with stones falling from the ridge flanks and being deposited there, stones tipping over, and stones from the surface of the fine domain being incorporated into the ridge (Fig. 10; see Supplement).

\subsection{Strain rates}

Figure 11 shows the sum of the horizontal strain rates. Horizontal extension indicates soil divergence and horizontal compression soil convergence. Divergence dominates on much of the inner parts of the fine domains, and convergence on the outer parts. Strain rates on the gravel rings are noisy, but it seems that divergence dominates on their upper parts, and convergence on their lower parts. Maximum surface strain rates are of the order of $0.1 \mathrm{yr}^{-1}$.

Net vertical soil transport upwards has to compensate for divergence, and vice versa, in order to keep the microrelief stable. Neglecting material compression or density changes, which is not necessarily valid for the soil investigated, a strain rate of $0.1 \mathrm{yr}^{-1}$ would, for instance, have to be compensated for by $0.01 \mathrm{~m} \mathrm{yr}^{-1}$ vertical material transport for a $10 \mathrm{~cm}$ thick layer, or $0.02 \mathrm{~m} \mathrm{yr}^{-1}$ for a $20 \mathrm{~cm}$ thick layer (cf. Hallet, 2013, for the choice of thickness). We note that, even if the above neglects are not entirely realistic, the vertical soil motion indicated by these scenarios is on the same order than the elevation changes found over $3 \mathrm{yr}$.

Table 1 lists some further estimates about vertical soil fluxes for the three fine domains, based on the horizontal strain rates. The total horizontal strain rates were classified into positive and negative ones (divergence and convergence), the respective areas (columns 3 and 6) and averages (columns 4 and 7) computed, and multiplied to arrive at vertical soil fluxes needed to compensate for horizontal strain of a layer with a given thickness (columns 5 and 8). The results of Table 1 are discussed below in the Discussion section.

\section{Discussion}

\subsection{Method}

For extracting the 3-D surface displacement field of sorted circles, we used a highly automatic time-lapse ground-based photogrammetric approach that yielded point clouds with a spatial resolution of about $1-2 \mathrm{~mm}$. The method proved to be very successful for measuring vertical and horizontal changes over $3 \mathrm{yr}$, but also suffers from some problems.

First, the differential GNSS measurements of ground control points were less accurate than the precision of the point cloud by an order of magnitude. Errors in ground control point positioning caused problems with absolute orientation of the final models, and in particular inhibited interpretation of absolute elevation changes and of the dynamics in areas of particularly small displacements. In future similar campaigns we thus suggest (i) using much longer metal rods as control points, or accurately survey some camera positions if possible; (ii) using a device to fix the GNSS receiver on the control points instead of holding it by hand as done here; (iii) complementing the GNSS measurements with optical levelling for millimetre-precision elevations; and (iv) using a stable bedrock outcrop as a local reference (can be found $\sim 1.5 \mathrm{~km}$ from the site).

Second, the image constellation chosen in the field was not optimized for SfM (the technique had not yet been widely established in 2007) and sharp contrasts in the 2007 images from solar shadows also caused some problems for the photogrammetric model computation, in particular the SIFT algorithm. 
Table 1. Surface strain rates and areas on the three circles. Horizontal extension (divergence) at the surface is an indicator for upwards material transport $(+)$, and vice versa $(-)$.

\begin{tabular}{|c|c|c|c|c|c|c|c|c|}
\hline 1 & 2 & 3 & 4 & 5 & 6 & 7 & 8 & 9 \\
\hline $\begin{array}{l}\text { Fine } \\
\text { domain }\end{array}$ & $\begin{array}{r}\text { Total } \\
\text { area } \\
\left(\mathrm{m}^{2}\right)\end{array}$ & $\begin{array}{r}\text { Area of } \\
\text { horizontal } \\
\text { compression } \\
\left(\mathrm{m}^{2}\right)\end{array}$ & $\begin{array}{r}\text { Mean } \\
\text { compression } \\
\left(\mathrm{yr}^{-1}\right)\end{array}$ & $\begin{array}{r}\text { Vertical } \\
\text { soil flux* } \\
\left(\mathrm{cm}^{3} \mathrm{yr}^{-1} \mathrm{~cm}^{-1}\right)\end{array}$ & $\begin{array}{r}\text { Area of } \\
\text { horizontal } \\
\text { extension } \\
\left(\mathrm{m}^{2}\right)\end{array}$ & $\begin{array}{r}\text { Mean } \\
\text { extension } \\
\left(\mathrm{yr}^{-1}\right)\end{array}$ & $\begin{array}{r}\text { Vertical } \\
\text { soil flux* } \\
\left(\mathrm{cm}^{3} \mathrm{yr}^{-1} \mathrm{~cm}^{-1}\right)\end{array}$ & $\begin{array}{r}\text { Total strain } \\
\text { rate over } \\
\text { fine domain } \\
\qquad\left(\mathrm{yr}^{-1}\right)\end{array}$ \\
\hline northern & 2.9 & 1.3 & -0.029 & -377 & 1.6 & +0.027 & +432 & +0.003 \\
\hline middle & 2.4 & 1.1 & -0.022 & -242 & 1.6 & +0.022 & +286 & +0.001 \\
\hline southern & 1.6 & 0.9 & -0.021 & -189 & 0.7 & +0.019 & +133 & -0.004 \\
\hline
\end{tabular}

* The vertical soil flux in column 5 corresponds to the area of horizontal compression, the flux in column 8 to horizontal extension. Vertical soil flux is given per centimetre of thickness of the horizontally moving layer and under the assumption of stable microrelief and the absence of density changes.

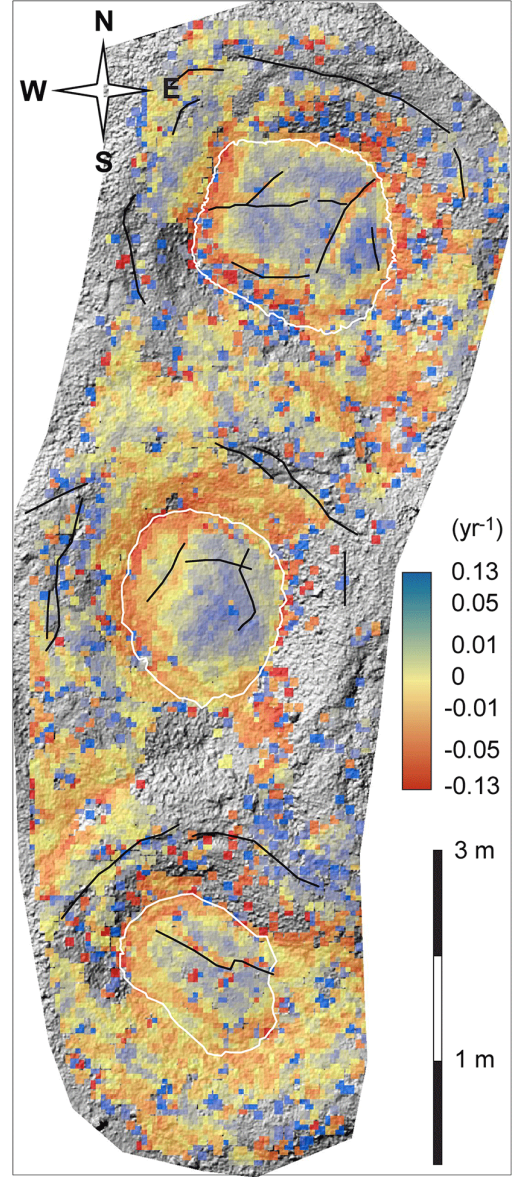

Figure 11. Sum of horizontal strain rates from the 2007-2010 displacement field. Computation has been based on the filtered displacement field (Fig. A1; see Appendix) and further filtered based on residuals of a redundant strain rate algorithm (see text). Blue colouring indicates horizontal extension (divergence); red indicates compression (convergence). The fine-coarse boundary is indicated in white, and the cracks in black. Note that, in order to highlight variations, the colour scale of strain rates is not linear. Background: hillshade of 2007.
Compared to the alternative solution of using a terrestrial laser scanner (TLS), photogrammetry offers somewhat higher resolution and precision, requires less equipment to be brought into the field, and is much cheaper - but is more demanding with respect to data processing (cf. Westoby et al., 2012). TLS would require several scan positions in order to image outside/inside of sorted circles margins. Direct comparison of field data acquisition and DEM quality has been done by Westoby et al. (2012) and James and Robson (2012), who find SfM technology to be faster in the field and of similar quality. However, TLS could have provided similar results as SfM in our study. Kociuba et al. (2014) provide a good impression of TLS results that can be achieved over stone circles.

\subsection{Microrelief}

While interpreting our results about the surface kinematics of three sorted circles, two significant uncertainties regarding temporal scale have to be considered, and these apply to this entire discussion. First, we observe these kinematics over $3 \mathrm{yr}$, which is a short time period compared to the evolution timescale of the circles (e.g. $>100 \mathrm{yr}$ from our streamline estimate). Thus, it is unclear to what extent the $3 \mathrm{yr}$ development measured is representative of the processes forming and maintaining the circles at longer timescales. Second, our change detection is based on photographs taken at two dates in Augusts, when the active layer is not at its deepest - judged from the degree-day sum at the time of photography compared to the total sum of the respective years (Fig. 4). The states of the surface of the study circles when photographed in 2007 and 2010 are therefore not representative of average annual conditions or even of average August conditions, and they may differ from one another. Short-term dynamics directly related to seasonal fluctuations in topography (from frost heave and thaw settlement processes) as well as stochastic variations in weather conditions are not picked up by our measurements.

With these restrictions, the initial geophysical finding in our study is that the microrelief of the circles is not stable 
through time. We observe an increase in relief, i.e. the elevation difference between the highest and lowest points, during the measurement period of on average $\sim 1.5 \mathrm{~cm} \mathrm{yr}^{-1}$, with increasing $\left(\sim 5 \mathrm{~mm} \mathrm{yr}^{-1}\right)$ or stable elevation in the centres of the fine domains and on parts of the gravel rings, whereas large areas of the fine domains, and especially the confluence between the coarse and fine domains, subside at rates of up to 1-1.5 $\mathrm{cm} \mathrm{yr}^{-1}$ (relative between 2007 and 2010). This observation is counterintuitive with respect to the similar visual appearance of the sorted circles with highly differing ages across different areas on Kvadehuksletta (Hallet and Prestrud, 1986), and is in disagreement with the basic assumption of long-term stable microrelief on which previous works (Hallet and Prestrud, 1986; Hallet et al., 1988; Hallet, 1998) have based their calculations of vertical soil velocities. As a steadily increasing microrelief is not sustainable in the long run, this suggests that, on shorter timescales of several years, the microrelief is able to change of the order of $\mathrm{cm} \mathrm{yr}^{-1}$ but seems to be systematically regularized over longer timescales.

Our data cannot determine whether the changes in microrelief could be caused by stochastic variations in yearto-year climatic conditions or are part of a long-term trend. There are no special events in the weather data from $\mathrm{Ny}$ Ålesund during this period or in permafrost temperature data from Janssonhaugen in Adventdalen, close to Longyeardalen (Fig. 4). The degree-day sum at the time of photography, however, was larger in 2007 than in 2010. As the microrelief decreases from the onset of thawing (snowmelt) from its maximum freezing inflation (Hallet, 2013), this could indicate that the microrelief was already more degraded at the time of photography in 2007 than in 2010. Active-layer monitoring data from Svalbard suggest that increasing active layer thickness during the recent decade (Christiansen et al., 2010; Marsz et al., 2013) and the extremely warm winterspring of 2005-2006 (Isaksen et al., 2007a) could also have altered ground conditions for years.

Also, the observed increase in slope within the inner domain, which is associated with the increase in microrelief, could, for instance, be compensated for over time by increased outward transport during high soil moisture conditions, or changes in the magnitude and pattern of frost heaving and settling. Our findings suggest significant spatiotemporal variations of the controlling processes within a timescale of a few years.

The general agreement between displacement direction and surface aspect (Fig. A4, Appendix) together with the lack of correlation between displacement rates and slope on the fine domains (Fig. A3) suggest, at least over our observation period, that gravitation can only explain to a limited extent the motion pattern found on the fine domains and that the slope there is thus not, or only to a limited extent, a driver of surface motion. In fact, it is the upwelling of soil that governs horizontal surface displacements and microrelief/slope. This is in agreement with the basic concepts behind the Kessler and Werner (2003) model.

\subsection{Horizontal displacement field}

The general surface velocity fields revealed in our data are similar to those derived from the existing point-based data (Hallet and Prestrud, 1986; Hallet et al., 1988; Hallet, 1998) and from the model by Kessler and Werner (2003). However, there are two important deviations. First, Kessler and Werner (2003) model fine-domain surface displacements as proportional to surface slope. The displacement fields of the three fine domains we investigate are, however, not closely related to slope (Fig. A3). In some sections, velocity vectors even point slightly upslope (Fig. A1). These deviations from predictions could easily be due to our slopes being unrepresentative of the slopes when lateral soil displacements are largest early in the thaw period, and due to the large seasonal changes in microrelief and slope during the thaw season. Hallet $(1998,2013)$ report frost heave during autumn of up to $10 \mathrm{~cm}$ in the centre of the fine domain, and differential frost heave could then easily invert part of the relief during winter and early summer.

Second, the difference we find in dynamic behaviour between neighbouring circles (of similar visual appearance) is striking and unexpected. In the southern circle, fine domain displacement is mainly at the lower detectable limit. The middle circle best displays surface velocity vectors pointing radially outwards from roughly the centre, in accordance with model predictions, but this origin of displacements surprisingly does not coincide with the highest topography within the fine domain (Fig. A1). Again, the August 2007 and 2010 elevation models are not likely to be representative of the topography during the period when largest seasonal displacements take place.

The general increase in displacement rates on the fine domains from the southern $\left(\sim 3-4 \mathrm{~mm} \mathrm{yr}^{-1}\right)$ to the northern circle $\left(\sim 2 \mathrm{~cm} \mathrm{yr}^{-1}\right)$ correlates with the proximity of the circles to the lake (Figs. 1 and 2) and could thus be due to higher soil moisture and water availability. In fact, in the study area (Fig. 2), circles closer to the lake are larger and partially joined with neighbouring ones, which might point to higher activity of these circles compared to those at a greater distance to the lake.

For the fine domain of the middle circle we find, by averaging all displacement vectors, an overall trend towards east $\left(\sim 3 \mathrm{~mm} \mathrm{yr}^{-1}\right)$ and thus net surface mass transport in this direction. The fine domain of the northern circle, however, has velocity vectors generally pointing towards south-west $\left(\sim 5 \mathrm{~mm} \mathrm{yr}^{-1}\right)$. (Uncertainties of absolute georeference, uncertainty of displacements on the gravel rings, and the speeds on some zones of the fine domain are all too high in order to be able to compute a meaningful overall displacement of the three circles.) 
Considerable complexity is evident in the 3 yr lateral displacements; given the roughly circular geometry of the patterned ground, the considerable motion in non-radial directions is surprising. For example, along the western gravel ring of the northern circle, displacements parallel the border, and displacements in the fine and gravel domains converge almost at right angle. A similar convergent displacement field is found on the western side of the middle circle. Our observations that, in places, stones move downslope at an angle to the maximum slope suggest significant border-parallel displacements (see also Fig. A4), which is consistent with the model by Kessler and Werner (2003).

Hallet (2013) found that over a period of $9 \mathrm{yr}$, displacement rates on the fine domains increase radially from the circle centre but decrease again after roughly two-thirds of the radius towards the fine-coarse boundary (cf. Washburn, 1989). At many sections of the fine domains, our results also show such a radial pattern, but clearly with strong spatial variations (Fig. A2). It is important to note, however, that the measurements by Hallet (2013) were based on stiff rods anchored at a depth of $0.2 \mathrm{~m}$, whereas we measure pure surface displacements.

\subsection{Soil convergence/divergence}

The strain rate computations (Fig. 11, Table 1) enable scenarios about the soil motion processes. Assuming that zones of horizontal divergence indicate zones of soil upwelling, and vice versa, surface areas of both types of vertical soil motion are roughly equal for the fine domains. The average horizontal extensions or compressions on the fine domains are $\sim 2$ $3 \%$. The sum of strain rates for each of the three fine domains is remarkably close to zero (Table 1, column 9). This means that the associated soil fluxes are roughly in balance for the fine domains (cf. Washburn, 1989) when neglecting soil density changes over time and spatial variations of the thickness of the horizontally moving layer.

Further under these above assumptions, the northern fine domain seems to have the largest soil turnover, the southern one the smallest. For a 10 [20] $\mathrm{cm}$ thick horizontal layer moving with surface velocities (cf. Hallet, 2013), the northern, middle and southern circles have a soil volume turnover of $\sim 4000[8000] \mathrm{cm}^{3} \mathrm{yr}^{-1}, \sim 2500[5000] \mathrm{cm}^{3} \mathrm{yr}^{-1}$ and $\sim 1500[3000] \mathrm{cm}^{3} \mathrm{yr}^{-1}$, respectively. On average over all three fine domains, these numbers equal to a vertical soil volume turnover of $\sim 0.12[0.25] \mathrm{m}^{3} \mathrm{~m}^{-2} 100 \mathrm{yr}^{-1}$. For a $25 \mathrm{~cm}$ thick horizontally moving top layer and a total depth of convecting soil of $1 \mathrm{~m}$ (Hallet, 2013), we estimate an average cycling time of soil of $\sim 300-400 \mathrm{yr}$, slightly lower than previous estimates (Hallet, 2013). Assuming a decrease of horizontal displacement with depth, as in fact observed from the tilt of vertical rods (Hallet, 2013), would, however, decrease the soil volume turnovers and increase the cycling times estimated. For horizontal speeds decreasing linearly to zero at $20 \mathrm{~cm}$ depth (i.e. average speed is half that of surface speed), the above scenario of a $10 \mathrm{~cm}$ block-like lateral surface motion might thus be a realistic one for the circles studied, and more than doubles the cycling times to $\sim 800 \mathrm{yr}$.

Due to the more erratic movement of stones on the gravel rings, strain rates cannot be computed reliably enough for significant parts of them. However, based on some sections, we estimate a similar rate of volume turnover compared to the fine domains, and thus the above estimates for turnover per $\mathrm{m}^{2}$ and century also hold roughly for the entire circle areas observed.

The two general positions of cracks on the circles - those on the gravel ring tops and those on the fine domains - are mostly in areas of extensive flow, as was expected (Fig. 11). As was also expected, the orientation of the cracks on the gravel rings is perpendicular to the direction of maximum extension. There is, however, no such clear relation on the fine domains, where some cracks are perpendicular to the direction of extension and some not. This could be a further hint that the 3 yr horizontal displacement field on the fine domains in particular is not fully representative of average long-term displacements. Also, the cracks on the fine domains could be related to vertical processes that are not directly reflected in our $3 \mathrm{yr}$ displacements and elevation changes, such as frost heave and subsidence, or upwelling of material. The same cracks are visible both in 2007 and 2010, and should thus reflect processes operating on a timescale larger than $3 \mathrm{yr}$.

\section{Conclusions}

We apply for the first time structure-from-motion technology (SfM) to periglacial patterned ground based on repeat terrestrial photography. This way we measure horizontal and vertical components of $3 \mathrm{yr}$ surface displacements over three sorted soil circles at Kvadehuksletta, Spitsbergen, with an accuracy of a few millimetres. Our results confirm the considerable potential of SfM for in situ studies of cryospheric and geomorphological surface processes, and specifically that it is possible to extract high-resolution 3-D surface displacement patterns of patterned-ground features, even over relatively short timescales. The error estimates for vertical precision of the models are of the order of $\pm 6 \mathrm{~mm}$, which is well below the actual relative displacements revealed for large parts of the investigated area.

Our results for horizontal displacements with rates of up to $2-3 \mathrm{~cm} \mathrm{yr}^{-1}$ for both the fine domains of the circles and the gravel rings around them overall confirm previous pointbased observations and inferences (Hallet et al., 1988), and model predictions (Kessler and Werner, 2003) of a radial convection cell-like circulation of inner parts and complementary circulation in the outer rings (Fig. 3). Also in agreement with prior observations and results from this model, high values of image correlation between the two measurement epochs, as well as visual inspection of the repeat orthoimages, point to highly coherent surface deformation on 
the fine domains; in contrast, image correlation values on the gravel ridges are lower due to stones or groups of stones sliding or tipping individually. However, over the observational period the velocity pattern found is less homogenous than expected from past observations and model results. Considerable complexity is evident in the $3 \mathrm{yr}$ lateral displacements. Given the regular round geometry, which is often the striking characteristic of sorted circles, the considerable motion in non-radial directions is somewhat surprising. On the other hand, it would help account for asymmetric development of circle shapes, as indeed also found in nature (Figs. 1 and 2). The asymmetric displacement fields, in particular on the northern circle, are the only potential sign of convergence between neighbouring circles that we find. The uncertainty in absolute georeference of our measurements and in defining the boundary between fine domains and gravel rings, even on the centimetre level, turned out to be too large to detect changes in circle shapes at a statistically significant level.

Microrelief on the circles is larger in 2010 than in 2007, with relative elevations stable or slightly rising by up to $0.7 \mathrm{~cm} \mathrm{yr}^{-1}$ in the circle centre and on the inner slopes of the gravel rings, but lowering by up to $1.5 \mathrm{~cm} \mathrm{yr}^{-1}$ at the outer parts of the fine domains and the directly adjacent lower portions of the gravel rings (Fig. 3). The shortterm change in microrelief found cannot be sustained over longer timescales as slopes would soon oversteepen and the relief would quickly diverge from the relatively consistent, low relief characteristic of sorted circles. Thus, the observed changes in topography suggest transient complexities in space and time in addition to a longer-term stable convection-like circulation of material. Our observation period is too short to allow further conclusions to be drawn about these complexities.

The sum of horizontal strain rates on the fine domains averages to approximately zero, roughly confirming that the soil convection within the stone circles is in equilibrium. Related soil turnover is roughly $0.1-0.2 \mathrm{~m}^{3} \mathrm{~m}^{-2} 100 \mathrm{yr}^{-1}$ with a cycling time of the total soil volume of several hundred years, in line with earlier estimates.
Our measurements confirm model findings by suggesting that the soil convection drives the horizontal surface displacements and the microtopography. The areas where the relative elevation rises are areas where modelled soil movement has an upward component (Kessler et al., 2001). According to this model, increasing surface relief is consistent with increasing the rate of soil convection within the sorted circles. Such an acceleration in soil circulation may have important implications, as it may tend to increase sequestration of soil organic carbon (Bockheim, 2007) and thus act as a negative feedback in a global warming scenario. Our calculations also show that the vertical soil motions associated with the convergence-divergence pattern measured at the surface are of the same order as the changes in microrelief found, and that increasing surface strain associated with increasing soil turnover is thus able to again regularize previous changes in microrelief.

The notable changes in microrelief of the investigated sorted circles as well as the inhomogeneous horizontal displacement field suggest that our study should be followed up, using the same methodology, by both more long-term year-to-year monitoring and more short-term measurements within freezing and thawing seasons. Ideally, these measurements should be complemented by supporting observations on subsurface conditions and motions, such as those by Hallet (2013). Such observations could include the vertical profile of lateral displacements, vertical soil motions, moisture conditions, soil thermal conditions, and spatio-temporal variations in active layer depth and freezing front. Also, the variations in displacement fields at scales larger than a single circle suggest that such monitoring should include a larger area. Drawing conclusions about absolute horizontal and vertical changes of the circles requires better georeference accuracies than were achieved in this test study, which can be done using centimetre-precision instruments and surveying strategies, and/or longer observation times. 


\section{Appendix A}
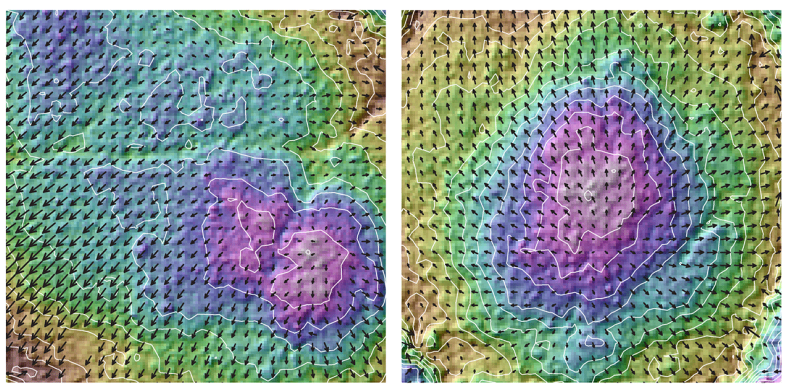

Figure A1. Details of displacement field and topography of northern (left panel) and middle (right panel) fine-domain centres. Finecoarse boundaries appear only in corners of the sections shown. Elevations are colour-coded (2007 elevations; 2010 elevations give a similar picture) and in addition indicated by $1 \mathrm{~cm}$ contours (white lines). Elevation range in both sections $\sim 10 \mathrm{~cm}$. Displacement vectors have $5 \mathrm{~cm}$ spacing and magnitudes of up to $2 \mathrm{~cm} \mathrm{yr}^{-1}$. Background: hillshade of 2007 DEM. Displacement vectors point upslope in some areas, and they cross some of the cracks, indicating partial advection of cracks.

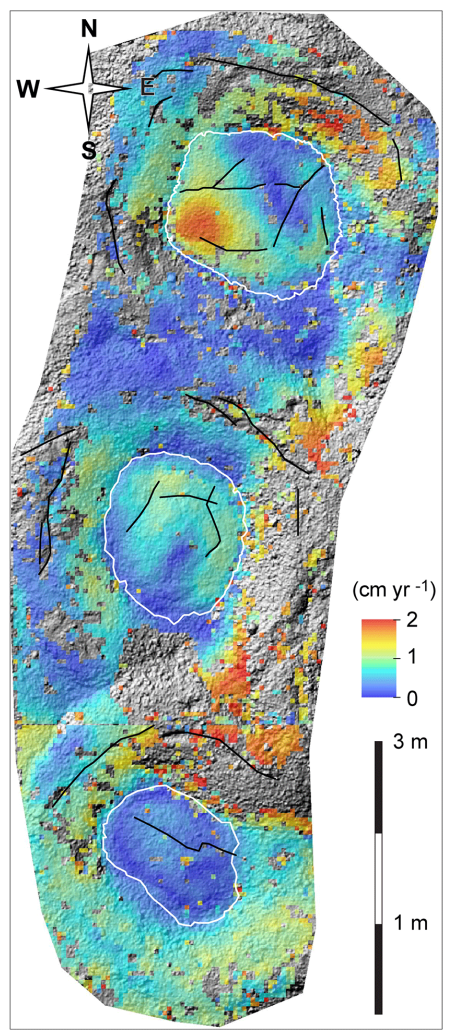

Figure A2. Displacement magnitude 2007-2010 on all three circles. Erratic displacements have been filtered out following Heid and Kääb (2012). Background: hillshade of 2007. See Supplement for animated GIFs of the 2007 and 2010 orthoimages.

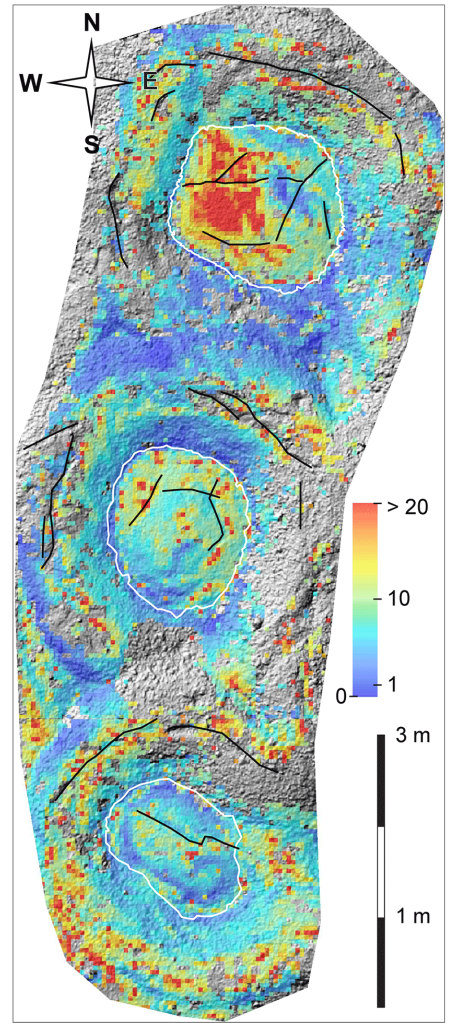

Figure A3. Ratio between displacement magnitude $\left(\mathrm{cm} \mathrm{yr}^{-1}\right)$ and tangent of slope. Typical ratios on the inner slopes of the gravel rings are 1-3; typical ratios on the fine domains and the ring tops are around 7 (green colours); at places ratios of 20 to 50 are found (red colours). Furthermore, would yellow colours not be around 15 or so? It is not clear what the relation to 7 is. Please make this clearer. The data illustrate the low correlation between slope and displacement magnitude on the circles.

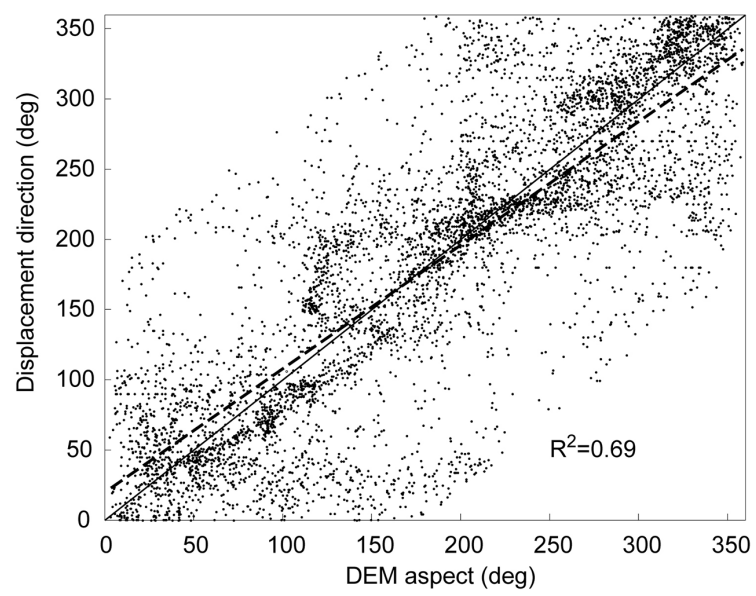

Figure A4. Displacement direction vs. DEM aspect on middle and northern circles (fine domains and gravel rings). Trend indicated by dashed line $\left(R^{2}=0.69\right)$. The missing data in the corners are due to the ambiguity in differences that occur at the transition from 359 to $360^{\circ}=0^{\circ}$. Differences larger than $180^{\circ}$ have been subtracted from $360^{\circ}$ to arrive at angles smaller than $180^{\circ}$. 


\section{The Supplement related to this article is available online at doi:10.5194/tc-8-1041-2014-supplement.}

\section{Author contributions}

A. Kääb and I. Berthling both designed the study and wrote the paper, and A. Kääb performed the data analysis. L. Girod constructed the photogrammetric models and products and edited the paper.

Acknowledgements. We are very grateful to J. Wasrud and T. Urke for their assistance during field work. We would also like to thank the two referees, B. Hallet and E. Hauber, for their exceptionally constructive, thoughtful and detailed comments on the paper. Their large effort significantly improved our study, and this is greatly acknowledged. The Norwegian Polar Institute and UNIS provided logistical support. T. Eiken helped with analysis of the GNSS data. Ground temperature data from Janssonhaugen were kindly made available by K. Isaksen, Norwegian Meteorological Institute. This study was funded by the Svalbard Science Forum (RIS 407 DIPGLOW) and the Research Council of Norway (project no. 446461 (RIS 3646 CAPP-dyn) and 185906). A. Kääb has received funding from the European Research Council under the European Union's Seventh Framework Programme (FP/2007-2013)/ERC grant agreement no. 320816. The software MicMac was kindly provided by the French National Institute of Geographic and Forest Information (IGN).

Edited by: J. Boike

\section{References}

Anderson, S. P.: Upfreezing in sorted circles, Western Spitsbergen, 5th International Conference on Permafrost, Trondheim, Norway, 666-671, 1988.

Bockheim, J. G.: Importance of cryoturbation in redistributing organic carbon in permafrost-affected soils, Soil Sci. Soc. Am. J., 71, 1335-1342, doi:10.2136/sssaj2006.0414N, 2007.

Bockheim, J. G., Walker, D. A., Everett, L. R., Nelsen, F. E., and Shiklomanov, N. I.: Soils and cryoturbation in moist nonacidic and acidic tundra in the Kuparuk river basin, Arctic Alaska, USA, Arctic Alpine Res., 30, 166-174, doi:10.2307/1552131, 1998.

Christiansen, H. H., Etzelmüller, B., Isaksen, K., Juliussen, H., Farbrot, H., Humlum, O., Johansson, M., Ingeman-Nielsen, T., Kristensen, L., Hjort, J., Holmlund, P., Sannel, A. B. K., Sigsgaard, C., Åkerman, H. J., Foged, N., Blikra, L. H., Pernosky, M. A., and Ødegård, R.: The thermal state of permafrost in the Nordic area during the International Polar Year 2007-2009, Permafrost Periglac., 21, 156-181, doi:10.1002/ppp.687, 2010.

Etzelmüller, B. and Sollid, J. L.: The role of weathering and pedological processes for the development of sorted circles on Kvadehuksletta, Svalbard - a short report, Polar Res., 9, 181-191, 1991.

Fonstad, M. A., Dietrich, J. T., Courville, B. C., Jensen, J. L., and Carbonneau, P. E.: Topographic structure from motion: a new development in photogrammetric measurement, Earth Surf. Proc. Land., 38, 421-430, doi:10.1002/Esp.3366, 2013.
Girod, L.: The use of SfM technologies in geosciences: MicMac for geologists, ENSG intership report, 32 pp., 2012.

Hallet, B.: Self-organization in freezing soils - from microscopic ice lenses to patterned-ground, Can. J. Phys., 68, 842-852, 1990.

Hallet, B.: Measurement of soil motion in sorted circles, Western Spitsbergen, 7th International Concerence on Permafrost, Yellowknife, Canada, 415-420, 1998.

Hallet, B.: Stone circles: form and soil kinematics, Philos. T. Roy. Soc. A, 371, 20120357, doi:10.1098/rsta.2012.0357, 2013.

Hallet, B. and Prestrud, S.: Dynamics of periglacial sorted circles in Western Spitsbergen, Quaternary Res., 26, 81-99, 1986.

Hallet, B., Anderson, S. P., Stubbs, C. W., and Gregory, E. C.: Surface soil displacement in sorted circles, Western Spitsbergen, 5th International permafrost conference, Trondheim, Norway, 770775,1988 .

Heid, T. and Kääb, A.: Evaluation of existing image matching methods for deriving glacier surface displacements globally from optical satellite imagery, Remote Sens. Environ., 118, 339-355, doi:10.1016/j.rse.2011.11.024, 2012.

Horwath, J. L., Sletten, R. S., Hagedorn, B., and Hallet, B.: Spatial and temporal distribution of soil organic carbon in nonsorted striped patterned ground of the High Arctic, J. Geophys. Res.Biogeo., 113, G03s07, doi:10.1029/2007jg000511, 2008.

Isaksen, K., Holmlund, P., Sollid, J. L., and Harris, C.: Three deep alpine-permafrost boreholes in Svalbard and Scandinavia, Permafrost Periglac., 12, 13-25, 2001.

Isaksen, K., Benestad, R. E., Harris, C., and Sollid, J. L.: Recent extreme near-surface permafrost temperatures on Svalbard in relation to future climate scenarios, Geophys. Res. Lett., 34, L17502, doi:10.1029/2007g1031002, 2007a.

Isaksen, K., Sollid, J. L., Holmlund, P., and Harris, C.: Recent warming of mountain permafrost in Svalbard and Scandinavia, J. Geophys. Res.-Earth, 112, F02s04, doi:10.1029/2006jf000522, 2007b.

James, M. R. and Robson, S.: Straightforward reconstruction of 3-D surfaces and topography with a camera: accuracy and geoscience application, J. Geophys. Res.-Earth, 117, F03017, doi:10.1029/2011jf002289, 2012.

Kessler, M. A. and Werner, B. T.: Self-organization of sorted patterned ground, Science, 299, 380-383, 2003.

Kessler, M. A., Murray, A. B., Werner, B. T., and Hallet, B.: A model for sorted circles as self-organized patterns, J. Geophys. Res.-Sol. Ea., 106, 13287-13306, 2001.

Kociuba, W., Kubisz, W., and Zagorski, P.: Use of terrestrial laser scanning (TLS) for monitoring and modelling of geomorphic processes and phenomena at a small and medium spatial scale in Polar environment (Scott River - Spitsbergen), Geomorphology, 212, 84-96, 2014.

Kääb, A.: Correlation Image Analysis Software (CIAS), available at: http://www.mn.uio.no/icemass, last access: 6 May 2014.

Kääb, A. and Funk, M.: Modelling mass balance using photogrammetric and geophysical data. A pilot study at Gries glacier, Swiss Alps, J. Glaciol., 45, 575-583, 1999.

Kääb, A. and Vollmer, M.: Surface geometry, thickness changes and flow fields on creeping mountain permafrost: automatic extraction by digital image analysis, Permafrost Periglac., 11, 315-326, 2000.

Kääb, A., Gudmundsson, G. H., and Hoelzle, M.: Surface deformation of creeping mountain permafrost, photogrammetric inves- 
tigations on rock glacier Murtèl, Swiss Alps, 7th International Permafrost Conference, Yellowknife, Canada, 531-537, 1998.

Marsz, A. A., Styszynska, A., Pekala, K., and RepelewskaPekalowa, J.: Influence of meteorological elements on changes in actice-layer thickness in the Bellsund region, Svalbard, Permafrost Periglac., 24, 304-312, doi:10.1002/ppp.1790, 2013.

Matsuoka, N., Abe, M., and Ijiri, M.: Differential frost heave and sorted patterned ground: field measurements and a laboratory experiment, Geomorphology, 52, 73-85, 2003.

MicMac: available at: http://logiciels.ign.fr/?-Micmac,3-, last access: 7 May 2014.

Nye, J. F.: A method of determining the strain-rate tensor at the surface of a glacier, J. Glaciol, 3, 409-419, 1959.

Peterson, R. A.: Stability analysis and numerical simulation of differential frost heave, 40, 277-298, doi:10.1007/s11004-0089150-z, 2008.

Peterson, R. A. and Krantz, W. B.: Differential frost heave model for patterned ground formation: corroboration with observations along a North American arctic transect, J. Geophys. Res.Biogeo., 113, G03S04, doi:10.1029/2007JG000559, 2008.

Pierrot-Deseilligny, M. and Clery, I.: Recent evolution in photogrammetry and $3 \mathrm{~d}$ modelisation of natural spaces, Université de Savoie, Collection EDYTEM, 12, 51-66, 2011.
Pierrot-Deseilligny, M. and Clery, I.: Some possible protocols of acquisition for optimal use of the "APERO" open source software in automatic orientation and calibration, Castelldefels, Spain, Tutorial, EuroCOW workshop, 8-10 February 2012.

Putkonen, J.: Soil thermal properties and heat transfer processes near Ny-Ålesund, northwestern Spitsbergen, Svalbard, Polar Res., 17, 165-179, 1998.

Schmertmann, J. and Taylor, R. S.: Quantitative data from a patterned ground site over permafrost, US Army Cold Regions and Engineering Laboratory, Hanover, NH, USA, 1965.

Tolgensbakk, J. and Sollid, J. L.: Kvadehuksletta, geomorfologi og kvartærgeologi 1:10000, Norsk Polarinsitutt, Oslo, 1987.

Washburn, A. L.: Geocryology. A Survey of Periglacial Processes and Environments, John Wiley, Washington/New York, 406 pp., 1980.

Washburn, A. L.: Near-surface soil displacement in sorted circles, Resolute area, Cornwallis-Island, Canadian High Arctic, Can. J. Earth Sci., 26, 941-955, 1989.

Westoby, M. J., Brasington, J., Glasser, N. F., Hambrey, M. J., and Reynolds, J. M.: "Structure-from-Motion" photogrammetry: a low-cost, effective tool for geoscience applications, Geomorphology, 179, 300-314, doi:10.1016/j.geomorph.2012.08.021, 2012. 